\title{
A description of teaching methods using an on-site instructor versus a distant site instructor to train laryngoscopy to medical students in Hanoi, Vietnam, from Omaha, Nebraska, by video communication
}

\author{
Wesley G. Zeger ${ }^{1}$, Chad E. Branecki ${ }^{1}$, Thang T. Nguyen ${ }^{1}$, Todd Hall², Ben Boedeker ${ }^{1 *}$, David Boedeker ${ }^{3}$ \\ and Michael C. Wadman'
}

\begin{abstract}
This study demonstrated a method to train medical students at Hanoi Medical School in airway management from Omaha, Nebraska, using tele-mentoring techniques. Correct placement of the endotracheal tube was documented by tele-broncoscopy following intubation. This technology may increase medical training capabilities in remote or developing areas of the world. Medical care delivery could be performed using this technology by tele-mentoring a lesser trained medical provider at a distant site enabling them to accomplish complex medical tasks.
\end{abstract}

\section{Introduction}

Currently, most procedural skills instruction for healthcare providers in Vietnam, as well as in most other developing countries, is provided by on-site personnel. The logistical challenges of placing skilled instructors at these distant sites limit the global dissemination of the latest best practices in patient care, and strategies are needed to expand the impact of high-quality instructors, advances in medical knowledge, and new technologies.

Training in airway management is a critical skill in medical education. With improved internet resources, virtual training from a medical center to remote sites may provide an efficient and cost effective way to perform essential skills training.

Previous studies describe student education in video intubation using on-site trainers and documented proper endotracheal tube placement by tele-broncoscopy, with a remote teacher providing real time guidance to the learner as the procedure is performed [1-3]. Confirmation of successful completion of the skill is necessary to ensure effective instruction. This study describes both

\footnotetext{
* Correspondence: boedeker1@gmail.com

'University of Nebraska Medical Center, Omaha, NE, USA

Full list of author information is available at the end of the article
}

instructions in laryngoscopy using a video laryngoscope to allow for off-site tele-mentoring and off-site confirmation of correct endotracheal tube placement by telebroncoscopy. The methodology of this study would allow the entire laryngoscopy training to be performed virtually.

\section{Methods}

After IRB approval, an audiovisual link using Vidyo, a HIPPA secure conferencing program (Vidyo, Inc., Hackensack, NJ) link was established between the Center for Advanced Technology and Telemedicine (CATT), University of Nebraska Medical Center (UNMC) in Omaha, Nebraska, and Hanoi Medical University (HMU) in Hanoi, Vietnam. Medical students in Hanoi were instructed via tele-mentoring by an instructor at CATT in Omaha, Nebraska, in how to perform an intubation. After receiving intubation instruction, students performed one intubation on an airway mannequin. The instruction session consisted of visual demonstration of the critical anatomic structures only, and the instructor refrained from any physical guidance with the students' intended to modify their laryngoscope grasp, lifting force trajectory, or intubating positions. The intubation was done using a Karl Storz video laryngoscope with a \#3 Macintosh blade. 


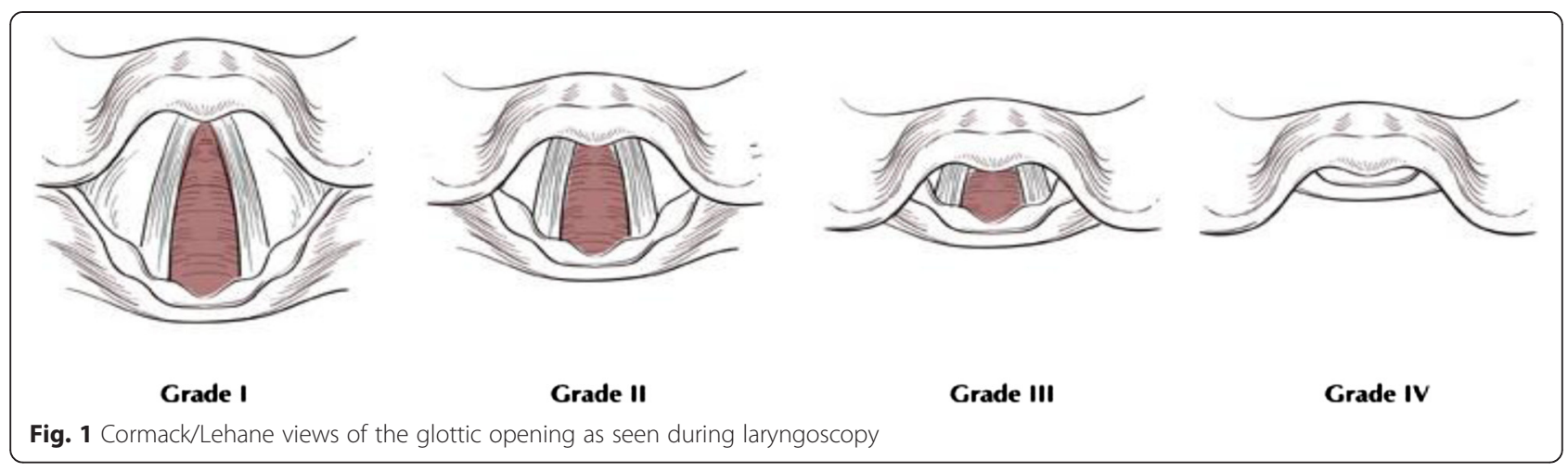

Students were timed in how long it took to perform the intubation. The Cormack/Lehane (C/L) view (Fig. 1) of the glottic opening observed by the student was recorded [4]. For the standard, on-site mentoring group in January 2015, eight medical student subjects performed video intubations after having been instructed by an on-site instructor. For the tele-mentoring group in March 2015, eight medical student subjects performed video intubations after instruction by an off-site instructor at CATT in Omaha, Nebraska, linked to HMU by videoconference. After completing the intubation, a bronchoscope, (linked to the Vidyo program by a Karl Storz C CAM and C HUB) was placed in the endotracheal lumen and advanced to the tip of the tube for confirmation of correct placement by the distant instructor at CATT. Proper endotracheal tube placement was confirmed by visualization of the tracheal rings, carina, or esophagus, depending on the level of the tip of the endotracheal tube (Fig. 1). Additional confirmation of correct tube placement was performed by the on-site instructor in Hanoi. Success or nonsuccess for each intubation was recorded. Teaching was in English, and the Vietnamese medical students spoke English as a second language. In terms of the statistical methods, researchers used averages to compare the two groups of data. This was deemed the best method for statistical comparison since it provides a holistic view of all participants.

\section{Results}

For the January 2015 standard on-site mentoring subjects, eight HMU medical students performed video intubations after having been instructed by an on-site instructor. As shown in Table 1, they had $75 \%$ success rate as documented by tracheal rings observation by telebroncoscopy. The average intubation time was $39.3 \mathrm{~s}$ (Table 1).

For the March 2015 tele-mentoring subjects, 11 HMU medical students performed video intubations after instruction by an off-site instructor at CATT in Omaha, Nebraska, linked to HMU by videoconference. Their success rate was $81.2 \%$, and average intubation time was $290 \mathrm{~s}$ (Table 2).

\section{Discussion}

One significant limitation of the study was the variable experience in airway management between the subject groups. Following completion of the experiment, the onsite instructors in Hanoi were informed that the second subject group in March had limited experience with intubation or laryngoscopy, compared to some significant laryngoscopy and intubating experience for the students in the first subject group participating in January.

As this is a preliminary report, the student numbers are too small to derive any statistical comparison between on-site versus distant site instruction. Review of the data shows that off-site, distant instruction appears to have resulted in longer times for intubation. As more students are trained by this project, using both on-site and distant site instruction, greater statistical comparison of the methods will be possible. However, this study demonstrates the feasibility of tele-mentoring for even the most novice learner in laryngoscopy.

Table 1 Direct mentoring trial: airway training performed by on-site instructor on-site at HMU

\begin{tabular}{|c|c|c|c|c|}
\hline & $\mathrm{C} / \mathrm{L}$ view grade & $\begin{array}{l}\text { Intubation } \\
\text { time }\end{array}$ & Result & $\begin{array}{l}\text { Confirmation } \\
\text { method }\end{array}$ \\
\hline Subject 1 & 1 & $34 \mathrm{~s}$ & + & $\begin{array}{l}\text { Tracheal } \\
\text { rings }\end{array}$ \\
\hline Subject 2 & 1 & $42 \mathrm{~s}$ & + & $\begin{array}{l}\text { Tracheal } \\
\text { rings }\end{array}$ \\
\hline Subject 3 & 1 & $24 \mathrm{~s}$ & + & $\begin{array}{l}\text { Tracheal } \\
\text { rings }\end{array}$ \\
\hline Subject 4 & NA & $23 \mathrm{~s}$ & - & NA \\
\hline Subject 5 & 1 & $16 \mathrm{~s}$ & + & $\begin{array}{l}\text { Tracheal } \\
\text { rings }\end{array}$ \\
\hline Subject 6 & 1 & $43 \mathrm{~s}$ & + & $\begin{array}{l}\text { Tracheal } \\
\text { rings }\end{array}$ \\
\hline Subject 7 & 3 & $108 \mathrm{~s}$ & - & NA \\
\hline Subject 8 & 2 & $25 \mathrm{~s}$ & + & $\begin{array}{l}\text { Tracheal } \\
\text { rings }\end{array}$ \\
\hline Total & $\begin{array}{l}5, \text { grade } 1 ; 1, \text { grade } 2 ; \\
1 \text {, grade } 3 ; 0 \text {, grade } 4 ; \\
1 \text { NA }\end{array}$ & $\begin{array}{l}\text { Average, } \\
39.3 \mathrm{~s}\end{array}$ & $\begin{array}{l}75 \% \\
\text { success, } \\
25 \% \text { fail }\end{array}$ & $\begin{array}{l}\text { 6-tracheal } \\
\text { rings, 2-NA }\end{array}$ \\
\hline
\end{tabular}


Table 2 Tele-mentoring trial: airway training performed by distant instructor at CATT/UNMC in Omaha, Nebraska, connecting to student at HMU by Vidyo link

\begin{tabular}{lllll}
\hline & C/L view grade & $\begin{array}{l}\text { Intubation } \\
\text { time }\end{array}$ & Result & $\begin{array}{l}\text { Confirmation } \\
\text { method }\end{array}$ \\
\hline Subject 1 & 1 & $97 \mathrm{~s}$ & + & Carina \\
Subject 2 & NA & $242 \mathrm{~s}$ & - & NA \\
Subject 3 & 3 & $231 \mathrm{~s}$ & - & NA \\
Subject 4 & 2 & $417 \mathrm{~s}$ & + & Carina \\
Subject 5 & 1 & $335 \mathrm{~s}$ & + & Carina \\
Subject 6 & 2 & $293 \mathrm{~s}$ & + & Carina \\
Subject 7 & 3 & $354 \mathrm{~s}$ & + & Carina \\
Subject 8 & 2 & $66 \mathrm{~s}$ & + & Carina \\
Subject 9 & 3 & $93 \mathrm{~s}$ & + & Carina \\
Subject 10 & 2 & $180 \mathrm{~s}$ & + & Carina \\
Subject 11 & 2 & $885 \mathrm{~s}$ & + & Carina \\
Total & 3, grade 1; 5, & Average, & 9 (81.8\%) & 9-carina, \\
& grade 2; 3rade & $290.2 \mathrm{~s}$ & success, 2 & 2-NA \\
& 3; 0, grade 4; & & $(18.1 \%)$ fail & \\
& 1 NA & & &
\end{tabular}

\section{Conclusion}

This project demonstrates airway management instruction for medical students using on-site instructors versus tele-mentoring by distant site instructors. Of note, onsite instruction of the January subject group was only visual demonstration of the critical anatomy structures, and the instructor had no physical contact with the students to modify the subject's intubating position or posture. The lack of any hands-on modification of the learners' grasp, positioning, and posture during the procedure is important in comparing on-site mentoring to tele-mentoring from the distant site. Future studies may define a role for applied virtual reality in guidance of these psychomotor actions.

\section{Competing interests}

The authors declare that they have no competing interests.

\section{Authors' contributions}

WZ led the program design team and assisted in writing the paper. CB assisted in writing the paper, assisted in program design, and assisted in drafting the protocol. TN assisted in performing distance training, assisted with translation during training, and assisted with conducting protocol. TH assisted in developing tele-mentoring training design, assisted in equipment configuration for tele-mentoring capabilities, and assisted in conduct of projects and writing the paper. BB assisted with project design, assisted with drafting the protocol, conducted multiple practices of the tele-video laryngoscope training sessions, and assisted with writing the paper. DB assisted with writing the paper, assisted in revising and editing the paper, and assisted in analyzing the data. MW assisted with performing distance training, assisted with data collection, assisted with writing paper, and assisted with program design. All authors read and approved the final manuscript.

\section{Authors' information}

Dr. Wesley Zeger, DO is a board certified emergency medicine physician. $\mathrm{He}$ is a member of the Department of Emergency Medicine faculty at UNMC. Dr. Chad Branecki, MD is a board certified medicine physician. He is the associate residency program director.
Thang Nguyen is an advanced practice registered nurse with the department of emergency medicine at UNMC.

SFC Todd Hall coordinates telemedicine projects to support the Department of Defense telemedicine mission from the Landstuhl Regional Medical Center. He also works in telemedicine NCOIC at the Landstuhl Regional Medical Center.

Dr. Ben Boedeker, DVM, MD, PhD, MBA is the director of the Center for Advanced Technology and Telemedicine at the University of Nebraska Medical Center (UNMC). He is a professor in the department of Anesthesiology at UNMC and is a retired Colonel from the medical corps in the US Air Force Reserve.

David Boedeker is a MPH candidate at the Columbia University Mailman School of Public Health. He has worked with the Center for Advanced Technology and Telemedicine for over nine years.

Dr. Michael Wadman, MD is a board certified emergency medicine physician. $\mathrm{He}$ is a ABEM oral examiner and was the founding program director for the emergency medicine residency program. He is the Vice Chairman of Education for the emergency medicine department and is the Associate Dean for Graduate Medical Education at UNMC.

\section{Acknowledgements}

The authors would like to thank Gail Kuper, Chief Operating Officer for the Center for Advanced Technology and Telemedicine, UNMC for assistance with this project.

\section{DOD Disclosure}

The views expressed in this manuscript are those of the author(s) and do not reflect the official policy or position of the Department of the Army, Department of Defense, or the US Government.

\section{Author details}

${ }^{1}$ University of Nebraska Medical Center, Omaha, NE, USA. ${ }^{2}$ Landstuhl Regional Medical Center, Landstuhl, DE, Germany. ${ }^{3}$ Columbia University Mailman School of Public Health, New York, NY, USA.

Received: 15 May 2015 Accepted: 29 September 2015

Published online: 01 December 2015

\section{References}

1. Berg BW, Beamis EK, Murray WB, Boedeker BH. Remote videolaryngoscopy skills training for pre-hospital personnel. Stud Health Technol Inform. 2009;142:31-3.

2. Walker MI, Walker RB, Morgan JS, Bernhagen M, Markin N, Boedeker BH. The use of virtual training to support insertion of advanced technology at remote military locations. Stud Health Technol Inform. 2011; 2011(163):688-90.

3. Boedeker BH, Bernhagen M, Miller DJ, Miljkovic N, Kuper GM, Murray WB. The combined use of Skype and the STORZCMAC Video Laryngoscope in field intubation training with the Nebraska National Guard. Stud Health Technol Inform. 2011;163:83-5.

4. Cormack RS, Lehane J. Difficult tracheal intubation in obstetrics. Anesthesia. 1984;39:1105.

\section{Submit your manuscript to a SpringerOpen ${ }^{\circ}$ journal and benefit from:}

- Convenient online submission

Rigorous peer review

- Immediate publication on acceptance

- Open access: articles freely available online

- High visibility within the field

- Retaining the copyright to your article

Submit your next manuscript at $>$ springeropen.com 